\title{
Tibério Semprónio Graco (162-133 a.C.) entre o voo das águias e a voracidade dos abutres ${ }^{1}$
}

\author{
JosÉ D'ENCARNAÇÃO *
}

\begin{abstract}
RESUMEN ABSTRACT
Este articulo procura mostrar como $T$.

Procura monstrar-se como $T$

Sempronio Graco intentó resolver, aprovechando la mejor coyuntura, los

problemas sociales, económicos y politicos de la República romana. Fue, sin embargo, más allá de su propia ambición y los tiempos no eran precisamente los idóneos para remontar su "vuelo de águila". De ahi

que, en el momento oportuno los «buitres»-«los optimates», 10 Semprónio Graco tentou resolver, aproveitando a melhor conjuntura, os problemas sociais, económicos e políticos da República romana. Foi, porém, longe de mais na sua ambicao e os tempos nao estavam preparados para o seu voo de águia. Dai que, no momento oporuno, os "abutres", dos optimates o tenham devorado.
\end{abstract}

devoraron

* Universidade de Coimbra.

1 O texto constitui a lição que, a 28 de Junho de 1999, proferi, em Mérida, no âmbito do XVI Curso de Verão da Universidad Nacional de Educación a Distancia; e repetida, a 8 de Julho seguinte, em Denia, integrada no $X$ Curso de Verăo da mesma universidade, subordinado agora ao tema "Protagonistas del Mundo Antiguo y Su Tiempo". Cumpre-me agradecer à Professora Pilar Fernández Uriel não apenas o convite para participar naqueles dois cursos como também por ter a gentileza de aceitar o texto para publicaçăo nesta prestigiada revista. 


\section{A SITUAÇÃO ECONÓMICA E SOCIAL}

O imperialismo militar e político contemporâneo e posterior às Guerras Púnicas visava a defesa da Pátria e o alargamento do ager publicus. Só que este alargamento, em vez de trazer solução para os problemas económicos e sociais, acabou por agravá-los.

Já desde, pelo menos, o séc. $V$ que patrícios e plebeus tinham ideias diferentes acerca da utilização dessa parte do território conquistado que o Estado reservava para si. Os patrícios preferiam que o ager publicus fosse domínio público, o que equivalia, na prática, a dizer que eles o poderiam usar em proveito próprio; os plebeus defendiam, pelo contrário, que o ager publicus thes fosse distribuído.

De acordo com o estipulado no plebiscitum flaminium (232 a. C.), o ager publicus considerava-se dividido em:

Agri scripturarii - Campos de florestas ou pastios, que o Estado adjudicava, mediante o pagamento de um tributo (vectigal).

Agri arcifinales - Terrenos cultiváveis, em estado de abandono, sem limites precisos, que o Estado arrendava mediante o pagamento da décima ou da quinta parte da colheita.

Agri adsignati - Terrenos cultivados, bem delimitados, que poderiam ter diversos destinos:

- ou eram arrendados, mediante uma comparticipação nos lucros por parte do Estado;

- ou eram denominados agri quaestorii, porque competia ao questor vendê-los em lotes;

- ou eram distribuídos gratuitamente ou sorteados entre diversos pretendentes, tanto de carácter colectivo como individual (viritários), recebendo, em caso de sorteio, a designação de ager colonicus.

Na prática, porém, era a minoria rica que o arrendava e que entregava, depois, a sua exploração às sociedades de publicanos.

Tudo isto traz como natural consequência a formação de latifúndios, cujos proprietários estão ausentes na cidade (como noutras épocas da História voltará a acontecer) e cujo cultivo é feito pelos escravos.

Por conseguinte, os pequenos e médios proprietários, a quem já a guerra trouxera graves prejuízos, ficaram sem possibilidades de subsistência e vêem-se obrigados a abandonar, em grande número, as suas terras. Demandam, pois, a cidade - uma cidade que se torna cinquietan- 
te", para usarmos a expressão de N. Rouland. Desenraizados, aí vão ter uma vida de ócio, sob a dependência de quem mais garantias thes oferecer. São, pois, novos clientes que os políticos aproveitarão a seu bel-prazer. A principio, a cidade ainda os ocupará na construção civil; mas, também aqui, é sol de pouca dura.

Entretanto, a nobilitas - a aristocracia fundiária - começa a reganhar o terreno que perdera nos inícios da República devido ao ardor reivindicativo da plebe. Doravante, só os plebeus "em boas graças" se poderão dar ao luxo de aspirar às magistraturas. Uma consequência, aliás, do clientelismo político que se reforça...

No entanto, com o mesmo ritmo com que a nobilitas se firma no poder, sobe o prestígio e a influência real dos cavaleiros (equites). Eles remontam à chamada reforma sérvia, mas não dispunham de qualquer órgão político próprio. O certo é que se começam a afirmar socialmente como "classe" muito antes de thes ser outorgado um estatuto juridico independente. E essa afirmação social prende-se com a cada vez maior importância dos publicanos.

Na realidade, a situação económica de Roma, agravada pelas despesas com obras públicas e com as forças armadas, determinou o lançamento de tributos sobre os povos conquistados. Ora, são as sociedades de publicanos que tomam de arrendamento essa tributação, sociedades em que os cavaleiros depressa se incluem porque vêem no aumento de riqueza uma forma segura de ascensão social ${ }^{2}$ e porque, por outro lado, aos senadores detentores de cargos políticos era vedada a participação em negócios (cf. Rouland 105-127).

\section{A SITUAÇÃO MILITAR}

A referida situação económica vai caracterizar-se, cada vez mais, pelo extremar de posições no concernente à posse de meios de subsistência.

Houvera confiscações impiedosas; durante a II Guerra Púnica, pereceram cerca de $16 \%$ dos homens capazes de pegar em armas. $O$ regime agrário instituído levou ao desaparecimento das classes intermédias do censo, que, segundo a reforma atribuída a Sérvio Túlio, alimentavam efectivamente as fileiras do exército romano.

A cavalaria, em si, como força de combate, estava em declinio, porque era confiada de preferência aos aliados romanos. 
Desta sorte, os ricos tudo fazem para fugir às suas obrigações militares - o tempo de serviço é longo, seis anos, por vezes o dobro; os pobres, por seu turno, não podem incorporar-se, porque não pertencem a nenhuma classe do censo. Assim, a falta de efectivos é alarmante.

Para a remediar, os governantes lançam mão de medidas de emergência e de legislação.

Como emergência, recorre-se ao tumultus, ou seja, à incorporação em massa, independentemente do censo; à evocatio, realistamento de técnicos necessários às operações militares; à coniuratio, alistamento em massa também mas sem o carácter de urgência e de desorganização do tumultus. Aqui, como a palavra indica, há um certo "tumulto»; na conjuração há, no final da incorporação, um juramento conjunto (de com+jurar).

No âmbito institucional, procede-se ao abaixamento do censo mínimo da $5{ }^{2}$ classe. Assim, temos notícia de que, ao tempo de Políbio (séc. II), o censo mínimo baixara de 11.000 para 4000 asses; e, no período de 133123, o limite deve ter sido fixado em 1500 asses.

Na prática, portanto, já muitos proletarii se incorporavam nas fileiras e - ideal de servir a Pátria começará a desvanecer-se. Os conquisitores, cujo papel aumentará de importância a partir da guerra social, munir-se-ão das listas oficiais dos mancebos a incorporar e não terão pejo em - por favor ou pelo dinheiro - isentarem do serviço quem não quiser alistar-se, substituindo-os por voluntários aliciados (cf. Gabba 1973, 10-25).

\section{A PERSONALIDADE DE TIBÉRIO SEMPRÓNIO GRACO}

Ao casar com a filha de Ápio Cláudio Pulcro, Tibério Graco ingressará num meio aristocrático formado por uma minoria da nobilitas que - em parte por oportunismo, em parte por conviç̧ão - deseja levar a cabo um certo número de reformas sociais e económicas exigidas pela conjuntura.

Essa minoria tem a vaga percepção de que, se tais reformas se não concretizarem, a situação pode degenerar em perigosa revolução. $E$ as causas estão bem à vista: o despovoamento rural, a proletarização das cidades, a baixa da curva demográfica, a subalimentação da maior parte da população, a desafeição dos aliados itálicos.

Aquando da sua viagem à Hispânia, em 137, integrado no exército de Mancino, Tibério Graco tem consciência nítida da gravidade da situação. Os campos da Etrúria, por onde passou, apresentavam um aspecto desolador; Mancino sofreu pesada derrota frente aos Arévacos, perto de 
Numância, e viu-se obrigado a capitular em condições vergonhosas. Um terceiro facto - a revolta dos escravos na Sicília (135) - veio confirmar as suas suspeitas.

Mas não foram só a sua experiência e os acontecimentos contemporâneos que geraram em Tibério Graco uma nova mentalidade. Para isso contribuiu também a formação intelectual que recebeu dos Gregos, designadamente de Blóssio de Cumas e de Diófanes de Mitilene. O primeiro era um estóico cuja filosofia sociopolítica hoje seria considerada de tipo socialista: é destino do Homem servir a sociedade; o Homem só é inteligivel na medida em que se integra na sociedade... Diófanes de Mitilene, por seu turno, propõe-lhe Péricles como exemplo - na eloquência, na acção política, na vida familiar.

E Tibério Graco decide renunciar ao luxo e ao prazer para se dedicar por inteiro à causa do povo: viver para o povo e agir pelo povo, utilizando como meio a palavra. A palavra que ele desenvolvia à maneira de Péricles, “o olímpico", com sobriedade, numa argumentação cerrada, donde emergiam, a espaços, cóleras geniais, fulgurantes como relâmpagos e estrondosas como trovões:

"As feras que vivem na Itália têm as suas tocas e os seus esconderijos onde se recolher; mas àqueles que combatem pela Itália e que pela Itália dão a própria vida, a esses homens nada thes é devido, a não ser a comunidade do ar e da luz. E, assim, privados de habitação, eles erram, vagabundos, acompanhados das mulheres e dos filhos.

Mentem os generais, quando exortam os soldados a que combatam contra os inimigos, porque dessa forma salvaguardam as suas sepulturas e as suas coisas sagradas! Mentem! E mentem porque, numa tão grande multidão da plebe romana, ninguém tem um altar paterno nem um monumento dos seus antepassados!... Eles combatem e eles morrem por aquilo que é alheio e pelas alheias riquezas. E, sendo chamados "senhores de toda a Terra", eles nem sequer possuem uma jeira de terreno!" (T. S. Graco in Plutarco).

\section{A ROGATIO SEMPRONIA}

Temos, pois, em síntese, factores favoráveis à nova legislação:

- uma conjuntura de larga e profunda crise;

- um homem definidor dessa crise;

- uma doutrina: o «socialismo» estóico; 

Pulcro;

_- um ponto de apoio: a minoria da nobilitas chefiada por Ápio Cláudio

- um momento (133): os grandes do "partido" conservador estão ausentes de Roma (o principal, Cipião Emiliano, combate em Numância).

A finalidade primária da Rogatio Sempronia não era económica. É possivel que Tibério Graco já tivesse pressentido a verdade histórica de que um êxito económico pode ser um fracasso social e que um fracasso económico pode ser um êxito social ${ }^{3}$. Tibério pretendia, por um lado, reduzir o número de proletarii e de subalimentados e, por outro, queria soldados robustos e ligados à terra. Era como que o reatar da antiga tradição de que só o vínculo do homem ao solo faz dele um verdadeiro combatente.

Por conseguinte, o meio mais adequado para obter esta dupla finalidade era proceder a uma redistribuição das terras. Por isso, a rogatio previa - na sequência, aliás, de legislação anterior:

1) a entrega aos proletarii do ager publicus usurpado;

2) a limitação da propriedade individual a 500 jeiras (ou seja, 125 hectares), limitação que podia ser recuada para mil (250 por cada filho, até ao máximo de dois);

3) a elevação de 7 para 30 jeiras $(=7,5$ ha) da dimensão dos lotes de terra a distribuir.

A nobilitas apercebeu-se desde logo que, se a rogatio passasse a lex, a sua preponderância social e política estava em cheque. Iniciou, por isso, uma ampla campanha de mobilização da opinião pública: a nova lei, dizia, prometia remediar uma injustiça mas, no fundo, cometia uma ainda maior, já que desapossava das suas terras aqueles que as tinham regado com o seu próprio suor, que as possuíam por direito inalienável por as haverem recebido como legado dos seus maiores ou como dote de suas esposas...

Para que a proposta de lei fosse votada nas condições mais favoráveis, Tibério Graco esperou pela Primavera de 133, altura em que o cônsul que Ihe era adverso estaria empenhado na luta contra os escravos da Sicília e em que afluiria a Roma a massa dos camponeses do ager Italicus.

Temos disso exemplos: na Inglaterra de meados do séc. XIX, a industrialização foi um espantoso êxito económico mas, socialmente, constituiu amplo fracasso: os proletários viviam miseravelmente, Na Rússia, as leis de Estaline tiveram sucesso económico mas, em 1953, a Rússia era, ainda, no plano social, um país subdesenvolvido. Na Argentina, o peronismo foi grande êxito social - Perón foi ao encontro de los descamisados e das suas necessidades - mas, do ponto de vista económico, o fracasso foi total. 
Sucedeu, porém, o imprevisto: Marco Octávio, um dos dez tribunos, opôs-lhe o seu veto. Impossivel prosseguir, nestas circunstâncias, apesar de a assembleia em bloco ser favorável. Tibério ameaça Marco Octávio, mas este resiste, porque (obviamente) estava apoiado nos optimates (os detentores do poder económico-político).

Ápio Cláudio Pulcro apela, em vão, para o Senado. A Tibério resta um meio: a demissão do tribuno rebelde e a sua substituição por outro, favorável à proposta.

A esse propósito, escreve Norbert Rouland:

Tibério Semprónio Graco, "atacando Octávio, tribuno da plebe que se transformara numa marioneta dos ricos, afirma, com uma força sem precedentes, o primado da soberania do povo, que este pode delegar, mas que também pode retomar sempre que os seus mandatários não cumpram" (p. 93).

Manobrado pelos ricos, Octávio opõe-se à reforma agrária; a Tibério só resta uma alternativa: demiti-lo, com o argumento de que não cumpre (Plutarco, Tibério Graco XV). A ideia era tipicamente grega, modificava «radicalmente a natureza do regime político romano, pela introdução de noções alheias ao seu funcionamento" (p. 93). "A deposição de Octávio repõe tudo em questão, ao fazer do povo a fonte do poder e o garante do seu exercício. O castigo de Tibério será à medida do seu crime" (p. 94) ${ }^{4}$.

Interessa salientar que, embora coroada de êxito imediato, a atitude de Tibério Graco assume, na conjuntura, uma enorme gravidade:

- nenhum exemplo do passado a sancionava e, entre os Romanos, o mos maiorum era lei;

- transferia dos magistrados para a assembleia popular a suprema autoridade efectiva;

- atentava contra o princípio da colegialidade, que a longa prática da República romana tinha confirmado;

- desfazia o equilíbrio em que, até aí, tinham vivido os diversos órgãos do Estado.

Na circunstância, não importava tanto que Tibério Graco tivesse querido devolver o tribunado à sua função primeira de defensor da plebe; o que interessava era verificar que ele, com esta maneira de agir, punha

\footnotetext{
Cf. Plutahco, Tibério Graco XVIII-XX.
} 
como que entre parênteses mais de dois séculos da história recente da instituição tribunícia.

E a sua audácia foi mais longe: fez eleger como triúnviros para superintenderem à aplicação da lei, além dele próprio, duas pessoas da sua família: o sogro e o irmão, Gaio. Os protestos não se fizeram esperar; mas, alheio a eles, Tibério Graco ousou de mais: recandidatou-se ao tribunado.

Nenhuma lei escrita o proibia, mas nenhum costume o sancionava de facto. Havia aqui um claro prenúncio do cesarismo: César nomear-se-á tribuno mais do que uma vez e o imperador Augusto assumirá o poder tribunício anualmente. O certo é que os tempos ainda não estavam preparados para isso. As velhas instituições de equilíbrio do Estado romano ainda se mantinham demasiado vigorosas para caírem ante a audácia de um jovem tribuno de trinta anos. O cesarismo só se implantará após doze guerras civis sucessivas, quando se verificar que é manifestamente incompatível a constituição de uma cidade-estado com o governo de um império.

Tibério Graco deixou-se perder pela sua audácia e pela sua antecipação do futuro. $E$ foi abandonado:

- pela plebe, já servida, na cidade onde integrava as clientelas, na província onde novas terras lhe tinham sido entregues;

- pelos tribunos, seus colegas, que começavam a não poder sustentar a sua supremacia sobre eles.

Vestido de luto, com o filho pela mão, rodeado de clientes, Tibério passeia no fórum, na tarde do dia em que se viu obrigado a adiar para o dia seguinte a assembleia que o deveria reeleger.

Mas a compaixão não foi suficiente, a demagogia não surtiu efeito e, no dia seguinte, no Capitólio, não era uma assembleia mas dois bandos de facções rivais que estavam reunidos.

A um sinal dado, o bando de Graco atacou o dos optimates.

Tibério, no aceso da refrega, desce pela encosta, enreda-se nos destroços dos bancos arrancados e é alcançado pelo seus perseguidores. Um dos colegas de tribunado assesta-Ihe uma pancada no crânio.

A oligarquia estava vingada.

Com ele morrem 300 dos seus partidários ${ }^{5}$.

5 Cf. Rouland 89-95. 


\section{CONCLUSÃO: ÁGUIA OU ABUTRE?}

O balanço desta experiência - e aqui, permita-se-me, refiro-me também à acção de seu irmão, Gaio Semprónio Graco - corre o risco de ser 'contaminado' pela projecção no séc. II a. C. dos esquemas mentais do nosso tempo.

Assim, há quem veja nos Gracos precursores do socialismo e quem os acuse de pura demagogia. Não terão sido nem uma coisa nem outra. Revolucionários ou simples reformadores? - poderá também perguntar-se.

Numa revolução, terão que confluir quatro elementos fundamentais: uma ideologia global, de base; uma programação a longo prazo; uma vontade eficaz de concretizar os objectivos fixados; e, finalmente, a transformação violenta da situação. A reforma apenas difere no último ponto, uma vez que preconiza uma mudança progressiva, específica e de âmbito juridico.

O que é revolucionário na política dos Gracos, afirma N. Rouland, não é tanto a tentativa de substituirem a classe dirigente pelo povo, mas sim os ataques que eles fazem a essa classe dirigente - porque toda a reforma aparentemente inofensiva é o elo duma cadeia: se se deixa cair o primeiro, toda a cadeia se vai desfazer.

Ao procurar explicar o sentido da legislação empreendida pelos Gracos, Ethella Hermon ${ }^{6}$ chama a atenção para a sua importância no plano juridico. Em seu entender, “(...) a legislação agrária dos Gracos teria tido como finalidade, entre outras, a de acabar com a ambiguidade jurídica que reinava no direito de propriedade sobre o ager publicus, de actualizar o direito romano que se desenvolvia muito menos lentamente que a realidade socioeconómica". Aliás, acrescenta $\mathrm{E}$. Hermon, é por isso que também a legislação após os Gracos não visa abolir essa legislação mas prosseguir no esforço de acabar com a ambiguidade jurídica reinante no que concerne à propriedade do ager publicus.

No entanto, do ponto de vista social, a clivagem manteve-se. E, do ponto de vista militar, a falta de efectivos também, o que se tornará ainda mais premente em face da iminência de novas campanhas. Em 123, chegarse-á a pensar no alistamento de crianças. Gaio Graco teve mesmo de fazer aprovar uma lei que proibisse a incorporação de menores de 17 anos ?.

In Ktema 11976 179-186.

Cf. Rouland 95-104. 
Tibério Semprónio Graco teve, pois, a argúcia da águia; dispôs do seu poder; faltou-lhe, porém, a medida. Que a águia lá no alto, plana, serena, e só desce em voo picado, mortífero, sobre a presa, quando a oportunidade é excelente.

Tibério Semprónio Graco precipitou-se, atacou antes do tempo - e, ao falhar a presa, estatelou-se. Os abutres andavam por perto, atentos também eles, à espera do desfecho, - e, quando ele se deu, não hesitaram: em bando desceram sobre o cadáver e partilharam-no serenamente.

Como a Natureza, também o curso da História muito dificilmente dá saltos - os que mandam detestam as convulsões à margem dos seus interesses.

Não o demonstram também - eloquentemente! - os acontecimentos recentes desta Europa de desencontros?...

\section{BIBLIOGRAFIA (muito sumária)}

Carcopino. Jerónimo: Autour des Gracques (Études Critiques). Paris, 1928.

DREYFus, R.: Essai sur les lois agraires sous la République romaine. 1898 (reimp. 1971).

FORSEN, B.: Lex Licinia Sextia de Modo Agrorum - Fiction or Reality? 1991.

GaBBA, Emílio: Esercito e Società nella Tarda Reppublica Romana, Florença, 1973.

- "Considerazioni sulla decadenza della piccola proprietà contadina nell'italia centro-meridionale del II sec. A. C.", Ktema 21977 269-284.

Garcia Pintlla, Ignacio J.: "Los Gracos considerados a través de los textos latinos de géneros no historicos", Habis 211990 93-99.

HERMON, Ethella: «La loi agraire de Tiberius Gracchus», Ktema 11976 179-186.

- "L'impérialisme romain à l'époque des Gracques", Ktema 41979 249-258.

NiCOLET, Claude: Les Gracques. Paris, 1967.

PINA POLO, F.: "La estructura agraria de la Peninsula Itálica en el siglo II a. C.", Veleia 41987 159-170.

Plutarco, Tibério Graco.

ROULAND, Norbert: Rome, Démocratie Impossible? (Les Acteurs du Pouvoir dans la Cité Romaine), Actes Sud, Herbert Nyssen, Éditeur, 1981, Le Paradou.

TAEGER, F.: Tiberius Gracchus (Untersuchungen zur römischen Geschichte und Quellenkunde), 1928. 